\title{
PAPER
}

\section{Incidence, risk, and case fatality of first ever stroke in the elderly population. The Rotterdam Study}

\author{
M Hollander, P J Koudstaal, M L Bots, D E Grobbee, A Hofman, M M B Breteler
}

J Neurol Neurosurg Psychiatry 2003;74:317-321

See end of article for authors' affiliations

.................

Correspondence to: Dr M M.B. Breteler, Department of Epidemiology and Biostatistics, Erasmus Medical Centre Rotterdam, PO Box 1738, 3000 DR Rotterdam, Netherlands; breteler@epib.fgg.eur.nl

Received 17 April 2002 Accepted in revised form 20 November 2002

\begin{abstract}
Objective: To estimate the incidence, survival, and lifetime risk of stroke in the elderly population. Methods: The authors conducted a study in 7721 participants from the population based Rotterdam Study who were free from stroke at baseline (1990-1993) and were followed up for stroke until 1 January 1999. Age and sex specific incidence, case fatality rates, and lifetime risks of stroke were calculated.

Results: Mean follow up was 6.0 years and 432 strokes occurred. The incidence rate of stroke per 1000 person years increased with age and ranged from $1.7(95 \% \mathrm{Cl} 0.4$ to 6.6$)$ in men aged 55 to 59 years to $69.8(95 \% \mathrm{Cl} 22.5$ to 216.6$)$ in men aged 95 years or over. Corresponding figures for women were $1.2(95 \% \mathrm{Cl} 0.3$ to 4.7$)$ and 33.1 (95\% Cl 17.8 to 61.6). Men and women had similar absolute lifetime risks of stroke (21\% for those aged 55 years). The survival after stroke did not differ according to sex.

Conclusions: Stroke incidence increases with age, also in the very old. Although the incidence rate is higher in men than in women over the entire age range, the lifetime risks were similar for both sexes.
\end{abstract}

lea $\mathrm{n}$ recent decades a decreasing trend in mortality of stroke has been observed. ${ }^{1-6}$ Nevertheless, stroke is among the leading causes of death in the Western countries and puts a large burden on healthcare systems. ${ }^{78}$ Stroke incidence increases with age, but information on the incidence and survival of stroke in the very old in the general population is limited. As populations are growing older this information is of importance, particularly for healthcare planners. ${ }^{9}$ Also, data on the risk of stroke during a person's life are lacking and are of interest on the individual level. We performed a large prospective study on the incidence of stroke in a population based cohort of elderly subjects aged 55 years or over, which enabled us to calculate incidence rates, survival, case fatality, and period and lifetime risks of stroke.

\section{METHODS}

\section{Study population}

This study was performed in the framework of the Rotterdam Study, a population based, single centre cohort study on chronic and disabling diseases in the elderly population. All inhabitants of Ommoord, a suburb of Rotterdam, aged 55 years or more were invited. People living in homes for the elderly were included..$^{10}$ Participation rate of those invited for the study was $78 \%$ and a total of 7983 subjects participated. The Medical Ethics Committee of Erasmus University approved the study. Written informed consent to retrieve information from treating physicians was obtained from all participants. Baseline measurements were obtained from 1990 to 1993 and consisted of an interview at home and two visits to the research centre for physical examination. During the interview a previous stroke was assessed by asking "did you ever suffer from a stroke, diagnosed by a physician?" Medical records of subjects who answered "yes" were checked and a previous stroke was considered to have occurred if medical records confirmed it. ${ }^{11}$ This study comprises a cohort of 7721 subjects who were free from stroke at baseline. Follow up for stroke was complete until 1 January 1999.

\section{Assessment of stroke}

Once subjects enter the Rotterdam Study they are continuously monitored for major events through automated linkage with files from the general practitioners. For this study information on stroke and death was used. Stroke is defined as rapidly developing clinical signs of focal or global disturbance of cerebral function with no apparent cause other than a vascular origin. When an event or death had been reported, additional information was obtained by interviewing the general practitioner and by scrutinising information from hospital discharge records in case of admittance or referral. Information from reports on all possible strokes was reviewed by two research physicians and a neurologist (PJK) who classified the stroke as definite, probable, or possible stroke. ${ }^{12}$ The stroke was definite if the diagnosis was based on typical clinical symptoms and neuroimaging excluded other diagnoses. The stroke was considered probable in case typical clinical symptoms were present but neuroimaging was not performed. For fatal strokes, other causes of death, especially cardiac should have been excluded. A stroke was classified as possible if clinical symptoms were less typical and neuroimaging was not performed, or if a cardiac cause of death could not be excluded in case of a fatal stroke. All reported transient ischaemic episodes also were reviewed in order to screen and classify all strokes. Subarachnoid haemorrhages were excluded. Until the end of follow up 202 definite, 130 probable, and 96 possible strokes occurred. We used definite and probable strokes in the analyses $(n=432)$. For subjects with a stroke, follow up was complete until 1 January 1999. Case fatality within 28 days was defined as death occurring within 28 days after onset of the stroke.

\section{Subtypes of stroke}

If the CT or MRI scan showed a cerebral haemorrhage or infarction the type of stroke was coded accordingly. In case of no abnormality on CT or MRI, the stroke was classified as cerebral infarction. Strokes without neuroimaging could be classified as possible haemorrhagic stroke or a cerebral infarction on the basis of the following symptoms. A possible haemorrhagic stroke was coded in case of sudden hemiplegia or other focal signs with permanent unconsciousness or death within hours. The stroke was classified as possible cerebral infarction if there was limited impairment (isolated aphasia, isolated weakness of one limb, isolated facial weakness, or isolated hemianopia), 


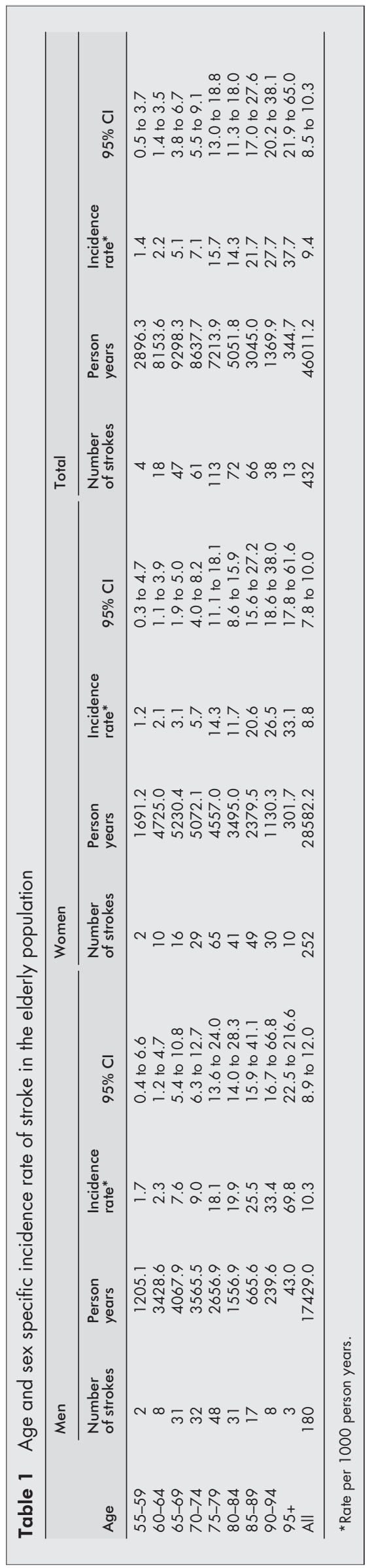

complete improvement within 72 hours or documented atrial fibrillation at time of the stroke.

\section{Data analysis}

The age specific incidence rate was obtained for each five year band by dividing the number of strokes by the total amount of person years attributed to a specific age category. The follow up ended either at occurrence of stroke, or at death, or at l January 1999, whichever came first. Participants who suffered from a subarachnoidal haemorrhage were censored on the date of the event. Incidence rates are given with 95\% confidence intervals (CI), assuming Poisson distribution. We calculated incidence and 28 days case fatality rates for subtypes of stroke in 10 year age ranges. For the calculation of 52 weeks case fatality rates we restricted ourselves to cases that occurred before 31 December 1998. We used Cox proportional hazards regression to investigate sex differences in risk of stroke and survival after stroke. In these analyses we adjusted for age at baseline and stroke, respectively. Survival after stroke was calculated using the Kaplan-Meier method. To calculate the absolute risk of stroke over time we took the competing risk of dying into account. Firstly, we obtained the stroke free survival at different ages from the cohort with the Kaplan-Meier method. Age at baseline was used as entry time and age at end of follow up, occurrence of stroke, or death as failure time. Then the cumulative absolute risk of stroke over a period was calculated as the integrated product of the age specific stroke incidences and the stroke free survival. ${ }^{13}$ The risk of stroke over time was calculated separately for men and women at ages $55,65,75$, and 85 years.

\section{RESULTS}

The mean follow up time was 6.0 years. We had 46011 person years of observation and 432 suffered from a first ever stroke. Of these 39 were primary intracerebral haemorrhages $(9.0 \%)$, 233 cerebral infarctions (53.9\%), and 160 unspecified strokes (37.0\%). A CT or MRI scan was performed in 256 (59.3\%) cases and in two cases necropsy was performed. The haemorrhages and infarctions were confirmed by neuroimaging in $74.4 \%$ and respectively $94.4 \%$. A total of 256 persons $(59.3 \%)$ were hospitalised. The incidence rate of stroke increased with age and ranged from 1.7 (95\% CI 0.4 to 6.6) in men aged 55-59 years to 69.8 (95\% CI 22.5 to 216.6 ) in men aged 95 or over (table 1). Corresponding rates for women were 1.2 (95\% CI 0.3 to 4.7 ) and 33.1 (95\% CI 17.8 to 61.6), respectively. Incidence rates were higher in men than in women over the entire age range. Adjusted for age at baseline the relative risks of stroke for men compared with women in partipants aged younger and older than 75 years were respectively 1.64 (95\% CI 1.26 to 2.15 ) and 1.36 (95\% CI 1.02 to 1.83 ). Table 2 shows that the incidence rate increased with age until the age of 85 for all subtypes of stroke. After age 85 , the proportion of unspecified strokes became very high and estimates of the frequency of subtypes of stroke less reliable. The proportion of hospitalised strokes decreased with age in both sexes (fig l).

\section{Case fatality}

The overall 28 days case fatality rate was $32.5 \%$ for all strokes, $12.4 \%$ for cerebral infarctions, and $33.3 \%$ for cerebral haemorrhages. Corresponding 52 week case fatality rates were 40.4, 23.6 , and $62.9 \%$. We observed no difference in survival after stroke between men and women (fig 2). Case fatality rates of stroke, cerebral infarction, and intracerebral haemorrhage increased with age (table 3 ).

\section{Lifetime risk of stroke}

Figure 3 shows survival and stroke free survival for 55 and 75 years old participants as observed in the total study cohort. The areas between the survival and stroke free survival curves represent the average time subjects live after a stroke. The area 
Table 2 Incidence rate of subtypes of stroke

\begin{tabular}{|c|c|c|c|c|c|c|c|c|c|}
\hline \multirow[b]{2}{*}{ Age } & \multicolumn{3}{|c|}{ Cerebral infarction } & \multicolumn{3}{|c|}{ Intracerebral haemorrhage } & \multicolumn{3}{|c|}{ Unspecified stroke } \\
\hline & $\begin{array}{l}\text { Number of } \\
\text { cases }\end{array}$ & $\begin{array}{l}\text { Incidence } \\
\text { rate* }\end{array}$ & $95 \% \mathrm{Cl} \dagger$ & $\begin{array}{l}\text { Number of } \\
\text { cases }\end{array}$ & $\begin{array}{l}\text { Incidence } \\
\text { rate* }\end{array}$ & $95 \% \mathrm{Cl} \dagger$ & $\begin{array}{l}\text { Number of } \\
\text { cases }\end{array}$ & $\begin{array}{l}\text { Incidence } \\
\text { rate* }\end{array}$ & $95 \% \mathrm{Cl} \dagger$ \\
\hline $55-64$ & 17 & 1.5 & 1.0 to 2.5 & 2 & 0.2 & 0.0 to 0.7 & 3 & 0.3 & 0.1 to 0.8 \\
\hline $65-74$ & 72 & 4.0 & 3.2 to 5.1 & 10 & 0.6 & 0.3 to 1.0 & 26 & 1.4 & 1.0 to 2.1 \\
\hline $75-84$ & 111 & 9.0 & 7.5 to 10.9 & 22 & 1.8 & 1.2 to 2.7 & 52 & 4.2 & 3.2 to 5.6 \\
\hline $85+$ & 33 & 6.9 & 4.9 to 9.8 & 5 & 1.1 & 0.4 to 2.5 & 79 & 16.6 & 13.3 to 20.7 \\
\hline All & 233 & 5.1 & 4.5 to 5.8 & 39 & 0.8 & 0.6 to 1.2 & 160 & 3.5 & 3.0 to 4.1 \\
\hline
\end{tabular}

* Rate per 1000 person years. $\dagger \mathrm{Cl}$, confidence intervals.

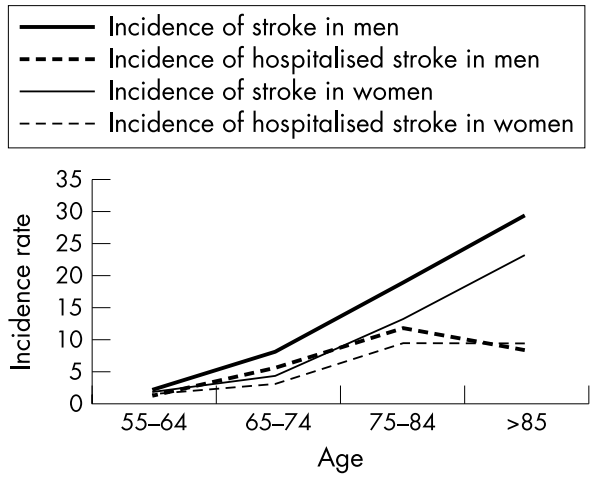

Figure 1 Incidence rate per 1000 person years for stroke and hospitalised stroke in relation to age in men and in women.

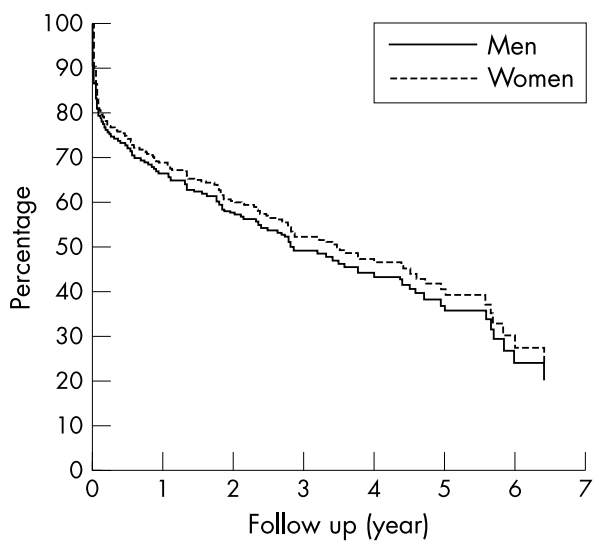

Figure 2 Cumulative survival after stroke according to sex, adjusted for age at stroke.

comprised 3.45 (95\% CI 2.93 to 3.97) years for men and 3.12 (95\% CI 2.69 to 3.55) years for women aged 55 years. Corresponding figures for persons aged 75 years were 2.16 (95\% CI 1.59 to 2.73 ) and 2.10 (95\% CI 1.63 to 2.57 ) years, respectively. Table 4 shows the cumulative incidence of stroke over time for men and women at different ages. The absolute risk of getting a stroke is nearly similar for men and women in all age categories, reflecting higher incidence rates, but shorter life expectancy in men as compared with women.

\section{DISCUSSION}

We found that the incidence rate of stroke was higher in men than in women over the entire age range. Nevertheless, as a net result of a shorter life expectancy and a higher incidence rate of stroke in men as compared with women, lifetime risks of stroke in men and women were similar at different ages.

\section{Case ascertainment}

Studies on incidence of stroke are vulnerable to selection bias. Although our participation rate was high (78\%), it is conceivable that non-participants had a higher risk profile for stroke. Consequently, our incidence figures most probably are conservative estimates of the true population incidence of stroke. Complete and accurate case ascertainment is crucial for the validity of the results of an incidence study. The prospective study design, standard definitions, defined study population, and multiple methods of case finding were in accordance with core criteria proposed by Malmgren and colleagues. ${ }^{14}$ Furthermore, the investigation and characteristics of stroke in this study fulfil criteria for optimal case ascertainment defined by researchers from the WHO MONICA stroke study. ${ }^{15}$ The follow up was complete for all participants and we used extensive and overlapping case finding methods to reduce selection bias in follow up. The proportion of non-hospitalised strokes in our study was 39\%. This is in accordance with the proportion (46\%) found by the Oxfordshire Stroke Project. ${ }^{16}$ Rotterdam with nearly 700000 inhabitants did not have a specific stroke admission strategy during the study period. The low admission rate was mainly explained by a shortage of hospital beds and by the fact that stroke units and stroke services were not yet widespread available and thrombolytic therapy not yet an established treatment. A weakness of our study that results from the fact that not all strokes were hospitalised is the comparatively low proportion of CT or MRI confirmed strokes. We observed that the proportion of unspecified strokes increased with age. Restriction to only neuroimaging confirmed strokes would have led to an underestimation of the incidence, especially in the very old. As only $75 \%$ of the intracerebral haemorrhages

Table 3 Twenty eight day case fatality for stroke, subtypes of stroke, and hospitalised strokes

\begin{tabular}{|c|c|c|c|c|c|c|c|c|}
\hline \multirow[b]{2}{*}{ Age } & \multicolumn{2}{|l|}{ Stroke } & \multicolumn{2}{|c|}{ Cerebral infarction } & \multicolumn{2}{|c|}{ Intracerebral haemorrhage } & \multicolumn{2}{|c|}{ Hospitalised stroke } \\
\hline & Number/total & $\%$ fatal & Number/total & $\%$ fatal & Number/total & $\%$ fatal & Number/total & $\%$ fatal \\
\hline $55-64$ & $2 / 22$ & 9.0 & $0 / 17$ & 0.0 & $1 / 2$ & 50.0 & $2 / 16$ & 12.5 \\
\hline $65-74$ & $15 / 108$ & 13.9 & $5 / 72$ & 6.9 & $1 / 10$ & 10.0 & $12 / 76$ & 15.8 \\
\hline $75-84$ & $33 / 105$ & 31.4 & $15 / 111$ & 13.5 & $8 / 22$ & 36.4 & $27 / 119$ & 22.7 \\
\hline $85+$ & $61 / 117$ & 52.1 & $9 / 33$ & 27.2 & $3 / 5$ & 60.0 & $22 / 45$ & 48.9 \\
\hline All & $111 / 342$ & 32.5 & $29 / 233$ & 12.4 & $13 / 39$ & 33.3 & $63 / 256$ & 24.6 \\
\hline
\end{tabular}


Table 4 Period and lifetime risk of stroke for 55, 65, 75, and 85 year old men and women taking competing risk of death into account

\begin{tabular}{|c|c|c|c|c|c|c|c|c|c|}
\hline \multirow[b]{2}{*}{ Age } & \multicolumn{8}{|c|}{ Period risk (\%) } & \multirow[b]{2}{*}{ Lifetime risk } \\
\hline & 5 year & 10 year & 15 year & 20 year & 25 year & 30 year & 35 year & 40 year & \\
\hline \multicolumn{10}{|l|}{ Men } \\
\hline 55 & 0.7 & 1.8 & 4.8 & 8.5 & 13.7 & 17.3 & 19.3 & 20.2 & 20.5 \\
\hline 65 & 2.2 & 6.0 & 11.8 & 15.9 & 18.2 & 19.1 & 19.4 & & 19.4 \\
\hline 75 & 6.9 & 12.5 & 15.7 & 17.0 & 17.4 & & & & 17.4 \\
\hline 85 & 6.0 & 8.3 & 9.0 & & & & & & 9.0 \\
\hline \multicolumn{10}{|c|}{ Women } \\
\hline 55 & 0.6 & 1.7 & 2.9 & 5.6 & 10.7 & 14.2 & 18.1 & 20.3 & 21.0 \\
\hline 65 & 1.1 & 3.9 & 9.4 & 13.1 & 17.2 & 19.6 & 20.3 & 20.4 & 20.4 \\
\hline 75 & 5.3 & 9.6 & 14.4 & 17.1 & 17.9 & 18.0 & 18.0 & & 18.0 \\
\hline 85 & 6.8 & 11.1 & 12.4 & 12.6 & & & & & 12.6 \\
\hline
\end{tabular}

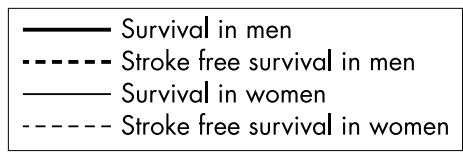

Subjects aged 55 years

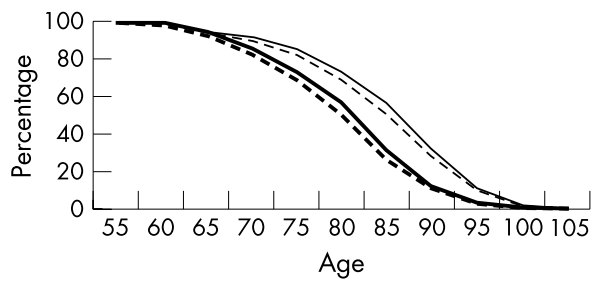

Subjects aged 75 years

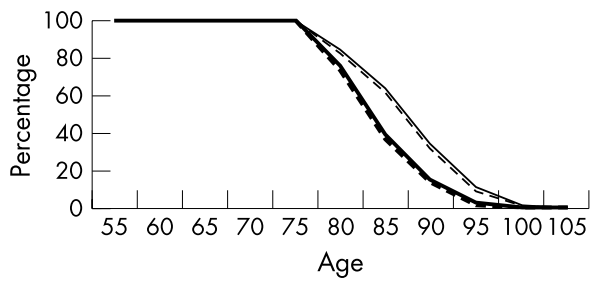

Figure 3 Survival and stroke free survival according to age and sex.

were confirmed by CT or MRI, the overall results on haemorrhages should be regarded carefully. Almost 95\% of the cerebral infarctions were CT confirmed. Therefore, we feel that the overall figures on cerebral infarctions are reliable. However, incidence figures of stroke subtypes in the very old are less reliable.

\section{Stroke incidence studies}

One hospital based study in the Netherlands (1978-1980) reported comparable, though slightly higher incidence rates of stroke than our study, but did not analyse the very old. ${ }^{17}$ Possibly the incidence has declined during the time interval between both studies. The incidence rates found in our study are in accordance with the results from other studies in Europe, although some studies reported lower incidence rates in subjects $>85$ years. ${ }^{16}{ }^{18-24}$ Studies in Eastern Europe reported higher incidence rates in subjects younger than 85 years, and lower rates in subjects older than $85 . .^{25-28}$ Incidence rates in Eastern European countries are known to be higher than in Western Europe. The lower rates in the very old in other studies might be explained by under-report of stroke in the elderly population, as we have shown that the proportion of hospitalised strokes declines with age. Incidence rates of stroke in subjects with a European background in Auckland, New Zealand (1992) were higher than in the Rotterdam Study. ${ }^{29}$ However, the North East Melbourne Stroke Incidence Study (1996-1997) reported similar rates. ${ }^{30}$ In our study the survival after stroke was equal in men and women. Most other studies did not find sex differences either..$^{291-34}$ We observed an increasing case fatality with age, and a higher case fatality of cerebral haemorrhages as compared with cerebral infarctions. These results are in accordance with results from other studies. ${ }^{21} 29333536$

\section{Lifetime risk of stroke}

Our calculations of lifetime risks of stroke were based on the assumption that characteristics of the cohort remain constant over time. They showed that although the incidence rate of stroke in men was higher than in women, the lifetime risk to get a stroke was similar when we took the competing risk of dying into account. The higher incidence rate of stroke is counterbalanced by shorter survival in men as compared with women. As a consequence, women on average are older when they get a stroke. In conclusion, stroke incidence increases with age, also in the very old. Although incidence rates in men were higher than in women over the entire age range, lifetime risks were similar.

\section{ACKNOWLEDGEMENTS}

This study has been supported by the Research Institute for Diseases in the Elderly, funded by the Ministry of Education and Science and the Ministry of Health, Welfare and Sports, through the Netherlands Organisation for Scientific Research (NWO). Dr M Hollander is supported by grant 904-61-091 of the NWO. Dr M L Bots is in part supported by grant 96.141 of the Netherlands Heart Foundation. Dr M M B Breteler is a fellow of the Royal Netherlands Academy of Arts and Sciences.

Authors' affiliations

M Hollander, A Hofman, M M B Breteler, Department of Epidemiology and Biostatistics, Erasmus Medical Centre, Rotterdam, Netherlands

M Hollander, P J Koudstaal, Department of Neurology, Erasmus Medical Centre

M L Bots, D E Grobbee, Julius Centre for General Practice and Patient Oriented Research, University Medical Centre Utrecht, Netherlands

Competing interests: none declared.

\section{REFERENCES}

1 Feinleib M, Ingster L, Rosenberg $H$, et al. Time trends, cohort effects, and geographic patterns in stroke mortality-United States. Ann Epidemiol 1993;3:458-65.

2 Wolf PA, D'Agostino RB, O'Neal MA, et al. Secular trends in stroke incidence and mortality. The Framingham Study. Stroke 1992;23:1551-5. 
3 Broderick JP. Stroke trends in Rochester, Minnesota, during 1945 to 1984. Ann Epidemiol 1993;3:476-9.

4 Howard G. Decline in stroke mortality in North Carolina. Description, predictions, and a possible underlying cause. Ann Epidemiol 1993;3:488-92.

5 Tuomilehto J, Sarti C, Torppa J, et al. Trends in stroke mortality and incidence in Finland in the 1970s and 1980s. Ann Epidemiol 1993;3:519-23.

6 Bonita R. Stroke trends in Australia and New Zealand: mortality, morbidity, and risk factors. Ann Epidemiol 1993;3:529-33.

7 Bonita R, Beaglehole R. The enigma of the decline in stroke deaths in the United States: the search for an explanation. Stroke 1996;27:370-2.

8 Bonita R. Epidemiology of stroke. Lancet 1992;339:342-4.

9 Bonita R, Beaglehole R. Monitoring stroke. An international challenge. Stroke 1995;26:541-2.

10 Hofman A, Grobbee DE, de Jong PT, et al. Determinants of disease and disability in the elderly: the Rotterdam Elderly Study. Eur J Epidemiol 1991;7:403-22.

11 Bots ML, Looman SJ, Koudstaal PJ, et al. Prevalence of stroke in the general population. The Rotterdam Study. Stroke 1996;27:1499-501.

12 Bots ML, Hoes AW, Koudstaal PJ, et al. Common carotid intima-media thickness and risk of stroke and myocardial infarction: the Rotterdam Study. Circulation 1997;96:1432-7.

13 Kalbfleisch JD, Prentice RL. The statistical analysis of failure time data. New York: Wiley, 1980.

14 Malmgren R, Warlow C, Bamford J, et al. Geographical and secular trends in stroke incidence. Lancet 1987; ii: 1 196-200.

15 Asplund K, Bonita R, Kuulasmaa K, et al. Multinational comparisons of stroke epidemiology. Evaluation of case ascertainment in the WHO MONICA Stroke Study. World Health Organization Monitoring Trends and Determinants in Cardiovascular Disease. Stroke 1995;26:355-60.

16 Bamford J, Sandercock P, Dennis M, et al. A prospective study of acute cerebrovascular disease in the community: the Oxfordshire Community Stroke Project 1981-86. 1. Methodology, demography and incident cases of first-ever stroke. J Neurol Neurosurg Psychiatry 1988:51:1373-80.

17 Herman B, Leyten AC, van Luijk JH, et al. Epidemiology of stroke in Tilburg, the Netherlands. The population- based stroke incidence register: 2. Incidence, initial clinical picture and medical care, and three-week case fatality. Stroke 1982;13:629-34

18 Wolfe CD, Giroud M, Kolominsky-Rabas P, et al. Variations in stroke incidence and survival in 3 areas of Europe. European Registries of Stroke (EROS) Collaboration. Stroke 2000;31:2074-9.

19 Kolominsky-Rabas PL, Sarti C, Heuschmann PU, et al. A prospective community-based study of stroke in Germany-the Erlangen Stroke Project (ESPro): incidence and case fatality at 1, 3, and 12 months. Stroke 1998;29:2501-6.

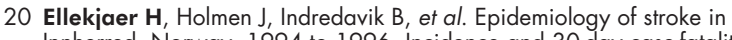
Innherred, Norway, 1994 to 1996. Incidence and 30-day case-fatality rate. Stroke 1997;28:2180-4.

21 Ricci S, Celani MG, La Rosa F, et al. SEPIVAC: a community-based study of stroke incidence in Umbria, Italy. I Neurol Neurosurg Psychiatry 1991;54:695-8.

22 Laurora G, Cesarone MR, De Sanctis MT, et al. Delayed arteriosclerosis progression in high risk subjects treated with mesoglycan. Evaluation of intima-media thickness. J Cardiovasc Surg (Torino) 1993;34:313-18.

23 Di Carlo A, Launer L, Breteler MM, et al. Frequency of stroke in Europe: a collaborative study of population- based cohorts. ILSA Working Group and the Neurologic Diseases in the Elderly Research Group. Italian Longitudinal Study on Aging. Neurology 2000;54:S28-33.

24 Thorvaldsen $\mathbf{P}$, Davidsen $M$, Bronnum-Hansen $\mathrm{H}$, et al. Stable stroke occurrence despite incidence reduction in an aging population: stroke trends in the danish monitoring trends and determinants in cardiovascular disease (MONICA) population. Stroke 1999;30:2529-34

25 Korv J, Roose M, Kaasik AE. Changed incidence and case-fatality rates of first-ever stroke between 1970 and 1993 in Tartu, Estonia. Stroke 1996;27:199-203

26 Feigin VL, Wiebers DO, Whisnant JP, et al. Stroke incidence and 30-day case-fatality rates in Novosibirsk, Russia, 1982 through 1992. Stroke 1995;26:924-9.

27 Czlonkowska A, Ryglewicz D, Weissbein T, et al. A prospective community-based study of stroke in Warsaw, Poland. Stroke 1994:25:547-51.

28 Eisenblatter D, Heinemann L, Classen E. Community-based stroke incidence trends from the 1970s through the 1980s in East Germany. Stroke 1995;26:919-23.

29 Bonita R, Broad JB, Beaglehole R. Ethnic differences in stroke incidence and case fatality in Auckland, New Zealand. Stroke 1997;28:758-61.

30 Thrift AG, Dewey HM, Macdonell RA, et al. Stroke incidence on the east coast of Australia: the North East Melbourne Stroke Incidence Study (NEMESIS). Stroke 2000;31:2087-92

31 Vemmos KN, Bots ML, Tsibouris PK, et al. Prognosis of stroke in the south of Greece: one year mortality, functional outcome and its determinants: the arcadia stroke registry. J Neurol Neurosurg Psychiatry $2000 ; 69: 595-600$.

32 Truelsen T, Bonita R, Gronbaek $M$, et al. Stroke incidence and case fatality in two populations: the Auckland Stroke Study and the Copenhagen City Heart Study. Neuroepidemiology 1998;17:132-8.

33 Bonita R, Broad JB, Beaglehole R. Changes in stroke incidence and case-fatality in Auckland, New Zealand, 1981-91. Lancet 1993;342:1470-3.

34 Lauria G, Gentile M, Fassetta G, et al. Incidence and prognosis of stroke in the Belluno province, Italy. First- year results of a community-based study. Stroke 1995;26:1787-93.

35 Vemmos KN, Bots ML, Tsibouris PK, et al. Stroke incidence and case fatality in southern Greece: the Arcadia stroke registry. Stroke 1999;30:363-70

36 Brown RD, Whisnant JP, Sicks JD, et al. Stroke incidence, prevalence, and survival: secular trends in Rochester, Minnesota, through 1989. Stroke 1996;27:373-80.

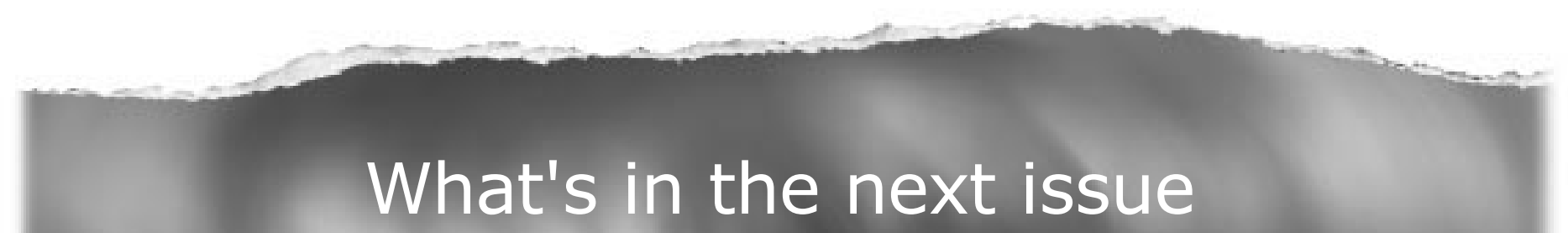

\section{Future content}

See which articles have just been accepted for publication and preview the table of contents for the next issue a month before it is published

\section{www.jnnp.com}

